\title{
Wild-type and mutant p53 differentially modulate miR-124/iASPP feedback following pohotodynamic therapy in human colon cancer cell line
}

\author{
Kuijie Liu ${ }^{1}$, Weidong Chen ${ }^{1}$, Sanlin Lei ${ }^{1}$, Li Xiong ${ }^{1}$, Hua Zhao ${ }^{1}$, Dong Liang ${ }^{2}$, Zhendong Lei ${ }^{1}$, Nanjiang Zhou ${ }^{1}$, Hongliang Ya* ${ }^{*, 1}$ and \\ Ying Liang*,3
}

Colorectal cancer (CRC) is a most common digestive system malignant tumor. p53 mutation has essential role in cancers and is frequently observed in CRC and presents a huge challenge. p53 mutation has been reported to attenuate the inhibitory effect of photofrin-based photodynamic therapy (PDT). p53 mutation-induced gain of function brings up the dysfunction of carcinogenic factors, including miRNAs. Our research found that PDT suppressed CRC cell viability, reduced the tumor size and prolonged the survival time, all of which could be attenuated by p53 mutation or deletion. After p53 mutation or deletion, several miRNA expression levels were downregulated, among which miR-124 was the most strongly downregulated, whereas iASPP expression was upregulated. p53 binds to the promoter of miR-124 to promote its expression and then inhibited iASPP expression, so as to amplify the inhibitory effect of PDT on wild-type p53 cells. In p53-mutant or -deleted cells, this binding no longer worked to promote miR-124 expression, and iASPP expression increased, finally resulted in promoted CRC cell viability upon PDT. The interactive modulation among miR and iASPP in p53-mutant or -deleted cells may serve as a crucial pathway, which mediates therapy resistance when $\mathrm{p} 53$ is mutated or deleted, in the process of PDT treatment of CRC.

Cell Death and Disease (2017) 8, e3096; doi:10.1038/cddis.2017.477; published online 12 October 2017

In 1997, photodynamic therapy (PDT) was newly classified as a fundamental method for treating tumors by Food and Drug Administration in United States of America, in addition to previously approved surgery, radiotherapy, chemotherapy and biochemical immunotherapy. ${ }^{1-3}$ It has been identified as one of the prime choices for advanced-stage esophageal cancer along with stenting by National Comprehensive Cancer Network. As for colorectal cancers (CRCs), PDT has also gained increasing attention for its efficacy in advanced cases. ${ }^{4-6}$ Although PDT has been more and more frequently applied in colon cancer treatment, unexpected challenges also arise, among which p53 mutation presented to be the most severe one.

p53 mutation can be commonly seen in malignancies, especially when patients are found to show resistance to chemotherapy or radiotherapy. ${ }^{7-9}$ Bond et al. ${ }^{10}$ revealed that p53 mutation is common in microsatellite stable, BRAF mutant CRCs. The p53 gene mutation is $0 \%(0 / 25), 44.8 \%(1(/ 38)$, $43.6 \%(34 / 78)$ and $42.1 \%(8 / 19)$, respectively, in normal mucosa tissue, colorectal adenomas, single lesion and multiple lesion of primary colorectal carcinomas, ${ }^{11}$ indicating that the mutation of p53-suppressor gene has a significant role in the procedure of colorectal tumorigenesis. In addition, it has been observed that tumors that bear a mutated p53 may be less responsive to PDT, indicating that $\mathrm{p} 53$ and its subsequent pathway may be well involved in terms of PDT efficacy and resistance. ${ }^{12}$ Fisher et al. ${ }^{13}$ revealed that wild-type p53 cells are significantly more sensitive to photofrin-mediated PDT. The effect of PDT on tumors is p53 independent. Therefore, by performing more investigation into the role of p53 in PDT treatment, especially the underlying signaling when p53 is mutated, we may further improve its efficacy.

Inhibitor of apoptosis-stimulating protein of p53 (iASPP), the oncoprotein inhibitory member of the ASPP family, could be inhibited so as to affect the CRC cell proliferation according to our previous study. ${ }^{14}$ In certain malignant cells, p53 mutation may trigger the activation of gain of function (GOF), bringing up the expression of some carcinogenic factors while knocking down other tumor suppressors. ${ }^{15}$ Some of these are transcriptional regulators of great importance in regulating tumor growth and cell apoptosis, such as miR-124. In fact, miR-124 has been repeatedly found involved in proliferation and apoptosis of cancerous cells, including CRC. ${ }^{16,17}$ The mutation of p53 may largely inhibit the expression of miR-124. So a question arises whether the interaction between p53 and $\mathrm{miR}-124 / \mathrm{iASPP}$ has a role in the process of PDT-induced cell apoptosis or when cancer cells show resistance to PDT therapy in $\mathrm{p} 3^{\text {mut }} \mathrm{CRC}$.

Once p53 is mutated or deleted, the expression level of miR-124 was downregulated, whereas iASPP expression was

\footnotetext{
${ }^{1}$ Department of General Surgery, The Second Xiangya Hospital, Central South University, Changsha, Hunan 410011, China; ${ }^{2}$ The People's Hospital of Zhengzhou University (Henan Provincial People's Hospital), Zhengzhou 450003, China and ${ }^{3}$ Department of Food Science and Engineering, Central South University of Forestry and Technology, Changsha, Hunan 410004, China

${ }^{*}$ Corresponding author: H Yao, Department of General Surgery, The Second Xiangya Hospital, Central South University, Changsha, Hunan 410011, China. Tel: +86-13808452603; Fax: +86-731-85533525; E-mail: yaohl0326@163.com

or Y Liang, Department of Food Science and Engineering, Central South University of Forestry and Technology, Shaoshan South Road, No. 498, Changsha, Hunan 410004, China. Tel: +86-13786101670; Fax: +86-731-85623038; E-mail: Liangying498@ 163.com

Received 21.4.17; revised 18.7.17; accepted 04.8.17; Edited by M Agostini
} 
upregulated. After p53 mutation or deletion in CRC cells, we found that the viability of CRC cells was upregulated. When PDT treatment was conducted, the $\mathrm{p} 53^{\text {mut }}$ or $\mathrm{p} 53^{-/-}$cells possess stronger viability than that of the $\mathrm{p} 53^{\mathrm{wt}}$ or $\mathrm{p} 53^{+/+}$cells. These findings revealed a novel perspective for the investigation of the p53's role in PDT efficacy and may lead to innovation of PDT by improving photosensitivity.

\section{Results}

The effect of PDT on cell viability, tumor size and survival percentage. To investigate the effect of PDT on the viability of $\mathrm{p} 53^{\mathrm{wt}}$ and $\mathrm{p5} 3^{\mathrm{mut}} \mathrm{CRC}$ cells, we determined the cell viability of HCT116, LoVo and RKO (p53 ${ }^{\mathrm{wt}}$ ) and HT29, DLD1 and SW480 ( $553^{\text {mut }}$ ) in response to PDT under a series of concentrations of photosensitizer (5-ALA) $(0,1.25,2.5,5,10$, $20 \mathrm{mg} / \mathrm{l})$. Results showed that the viability of all CRC cells was inhibited in response to PDT treatment in a concentration-dependent manner. Moreover, the viability of p53 $3^{\text {wt }}$ cells was inhibited more strongly, compared with the p53 $3^{\text {mut }}$ cells (Figure 1a). Next we determined the viability of p53 ${ }^{\text {wt }}$ (RKO) and p53 ${ }^{\text {mut }}$ (HT29) at 24 and $48 \mathrm{~h}$ in the absence or presence of PDT treatment. PDT treatment significantly suppressed the cell viability of RKO and HT29 cells, compared with PDT $(-)$ group $(\& \& P<0.01)$. Besides the cell viability of the $p 53^{\text {mut }}$ CRC cell line HT29 was always much higher than that of the $\mathrm{p} 53^{\mathrm{wt}} \mathrm{RKO}$, either in the absence or presence of PDT treatment (\#\#P<0.01; Figure 1c). Then we transfected HCT116 cells with $\mathrm{p} 53^{\text {wt }}$ shRNA or shRNA NC (negative control) in the presence or absence of PDT treatment and verified the p53 protein levels in the indicated cell lines using western blotting assays. Results showed that p53 protein was significantly reduced in $p 53^{\text {wt }}$ shRNAtransfected HCT116 cells and ${\mathrm{p} 53^{-/}}^{-1} \mathrm{HCT} 116$ cells (Figure 1b). Next, we determined the cell viability by using Cell Counting Kit-8 (CCK-8) assays to evaluate the effect of p53 ${ }^{\text {wt }}$ knockdown on cell viability. Results showed that PDT treatment significantly suppressed the viability of HCT116 cells in all groups $(\& \& P<0.01)$; however, the cell viability of p53 ${ }^{\text {wt }}$ shRNA-transfected cells was less strongly suppressed $(\# P<0.05, \# \# P<0.05)$ (Figure 1d). Similar results were

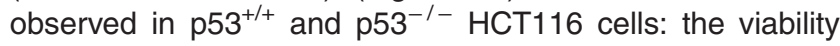
of all CRC cells was suppressed by PDT treatment $(\& \& P<0.01)$, and the viability of $\mathrm{p} 53^{-1-}$ cells was suppressed less strongly $(\# P<0.05, \# \# P<0.05)$ (Figure $1 \mathrm{e})$.

Then the volumes of the tumor derived from RKO $\left(\mathrm{p} 53^{\mathrm{wt}}\right)$ of HT29 (p53 $^{\text {mut }}$ ) cell were measured from day 3 to day 27 every 2 days. Results showed that the tumor volumes without PDT treatment were increased, while the tumor volumes were reduced by PDT treatment on day 7 and slowly increased at the later time points (Figures $1 \mathrm{f}$ and $\mathrm{g}$ ). In addition, the tumor volumes of $\mathrm{p} 53^{\mathrm{mut}}$ and $\mathrm{p} 53^{-/-}$cells origin were increased more strongly compared with those of the $\mathrm{p} 53^{\mathrm{wt}}$ and $\mathrm{p} 53^{+/+}$ cells (Figures $1 f$ and $g$ ). Results of the survival analysis showed that the survival percent of the RKO $\left(p 53^{\mathrm{wt}}\right)+$ PDT group was the highest, while the HT29 (p53 ${ }^{\text {mut }}$ ) group possessed the lowest survival rate (Figures $1 \mathrm{f}$ and g). Similar

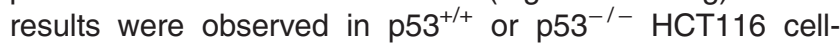
derived tumors (Figures $1 \mathrm{f}$ and $\mathrm{g}$ ). The data suggested that p53 mutation or knockout could promote the CRC cell viability and reduce the sensitivity of CRC cells to PDT treatment.

Screening and verification of candidate miRNAs for p53. GOF mutant p53 proteins can transcriptionally regulate the expression of a large plethora of target genes and also transcriptionally regulate the expression of microRNAs, small non-coding RNAs that regulate gene expression at the posttranscriptional level. ${ }^{18}$ To search for the candidate miRNAs that could be regulated by $\mathrm{p53}$, online tools, including miRWalk, miRanda, RNA22 and Targetscan, were used. Several miRNAs were proposed, among which seven of them were reported to be related to p53: miR-140, miR-30b, miR-3151, miR-506, miR-124, miR-30c, and miR-663b ${ }^{19-24}$ (Figure 2a). The expression levels of these miRNAs were determined in p53 ${ }^{\mathrm{wt}}, \mathrm{p} 53^{\mathrm{mut}}, \mathrm{p} 53^{+/+}$and $\mathrm{p} 53^{-/-}$ cells by using real-time PCR assays. In p53 ${ }^{\text {mut }}$ cell line HT29, the expression levels were significantly downregulated except miR-3151 and miR-663b (which were significantly upregulated), compared with $\mathrm{p} 53^{\mathrm{wt}}$ cell line RKO (Figure $2 \mathrm{~b}$ ). Similar results were observed in $\mathrm{p} 53^{+/+}$and $\mathrm{p} 53^{-/-}$cells (Figure $2 \mathrm{c}$ ): the expression levels of miR-3151 and miR-663b were

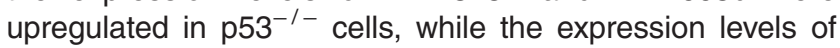
miR-140, miR-30b, miR-506, miR-124 and miR-30c were

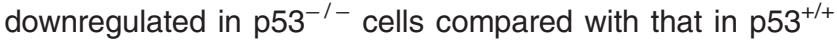
cells. Among the five downregulated miRNAs, miR-124 showed to be the most strongly downregulated in $\mathrm{p} 53^{\mathrm{mut}}$

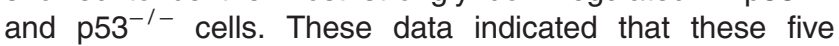
miRNAs could be inhibited after p53 mutant or knocked out, and miR-124 was the most strongly suppressed one.

The effect of PDT on miR-124 and iASPP mRNA expression. We revealed that the expression levels of miR-124 and iASPP were altered in a p53 contentdependent manner in tumor tissues, and then we further investigated the effect of PDT on miR-124 and iASPP expression in mice tumors that were derived from different tumor cells. Expression levels of iASPP mRNA were upregulated in a time-dependent manner in all kinds of mice tumors

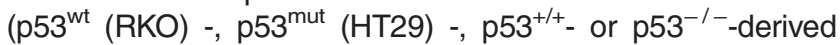
mice tumors) without PDT treatment (Figures $3 a$ and $c$ ); under PDT treatment, the expression of iASPP mRNA was downregulated to a valley value on day 7 by PDT treatment and returned gradually to higher levels at later time points; however, the expression levels of iASPP were lower in the PDT treatment groups than that in the non-PDT treatment groups (Figures $3 a$ and $c$ ). In the absence of PDT treatment, miR-124 expression was downregulated in a time-dependent manner in all kinds of mice tumors (p53 ${ }^{\text {wt }}$ (RKO) -, p53 $3^{\text {mut }}$

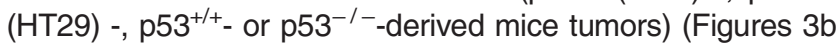
and d); in the presence of PDT treatment, miR-124 expression was upregulated to a peak value on day 7 by PDT treatment, and fell down gradually to lower levels at later time points; however, miR-124 expression in the PDT treatment groups was higher than that in the non-PDT treatment groups (Figures $3 b$ and $d$ ).

The influence of miR-124 or iASPP on $\mathrm{p} 53^{\mathrm{wt}} / \mathrm{p} 53^{\mathrm{mut}}$ and

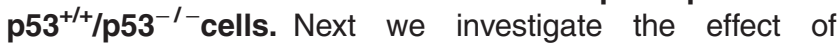
miR-124 on the viability of $\mathrm{p} 53^{\mathrm{wt}} / \mathrm{p} 53^{\mathrm{mut}} \mathrm{CRC}$ cells in 


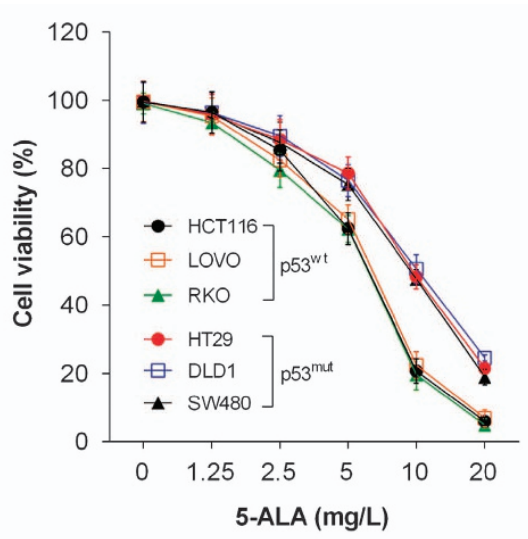

b HCT116

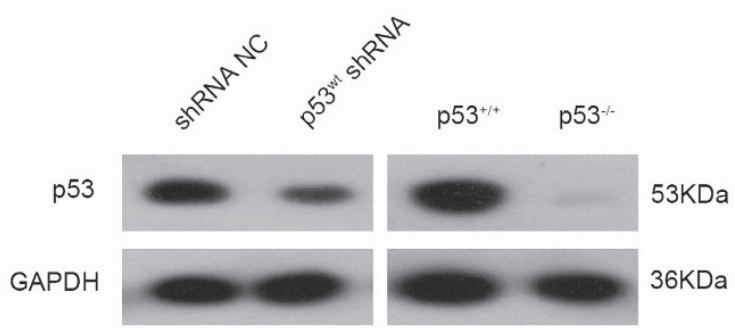

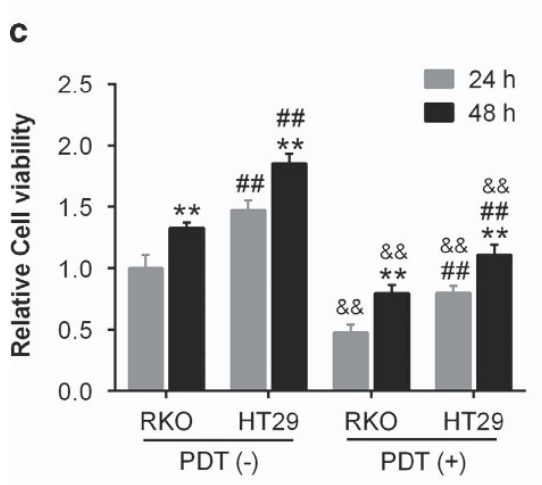

f d

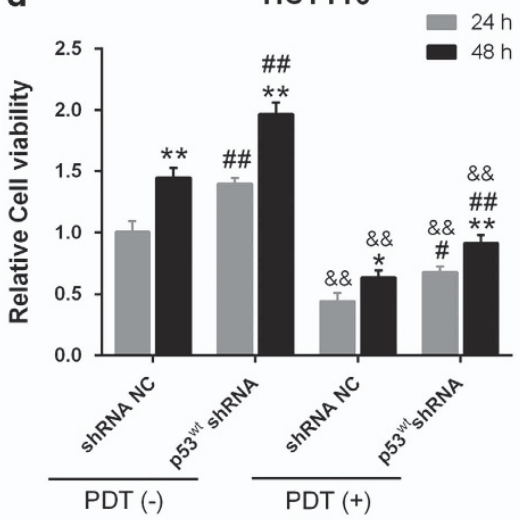

e

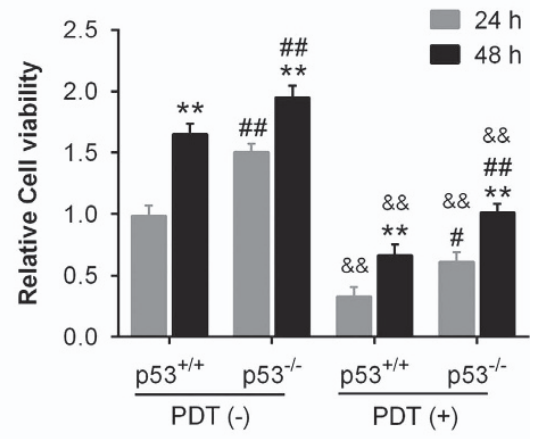

RKO VS HT29
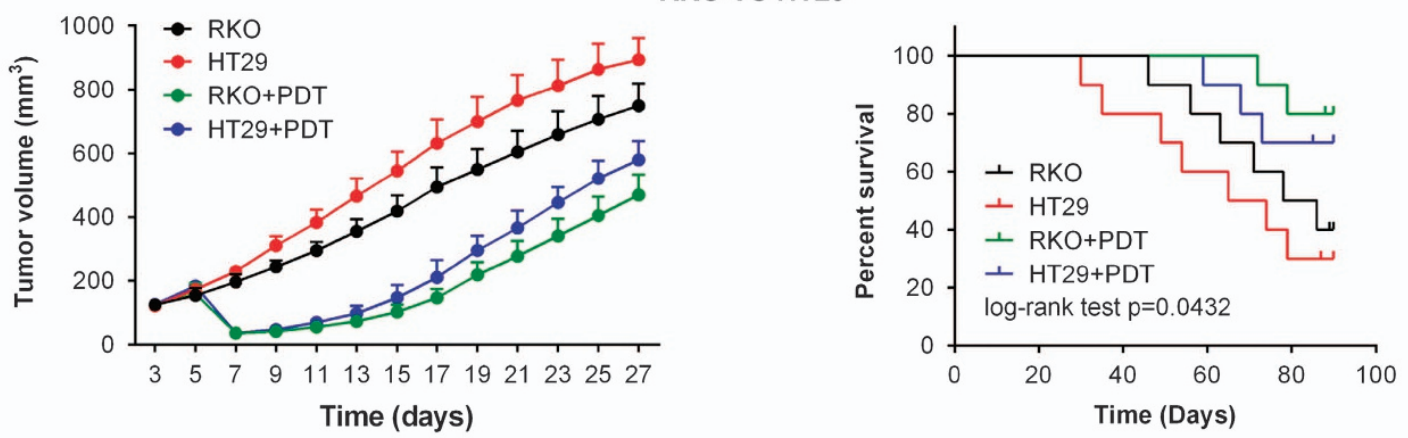

g

HCT116 $\mathrm{P}^{2+/+}$ VS P53
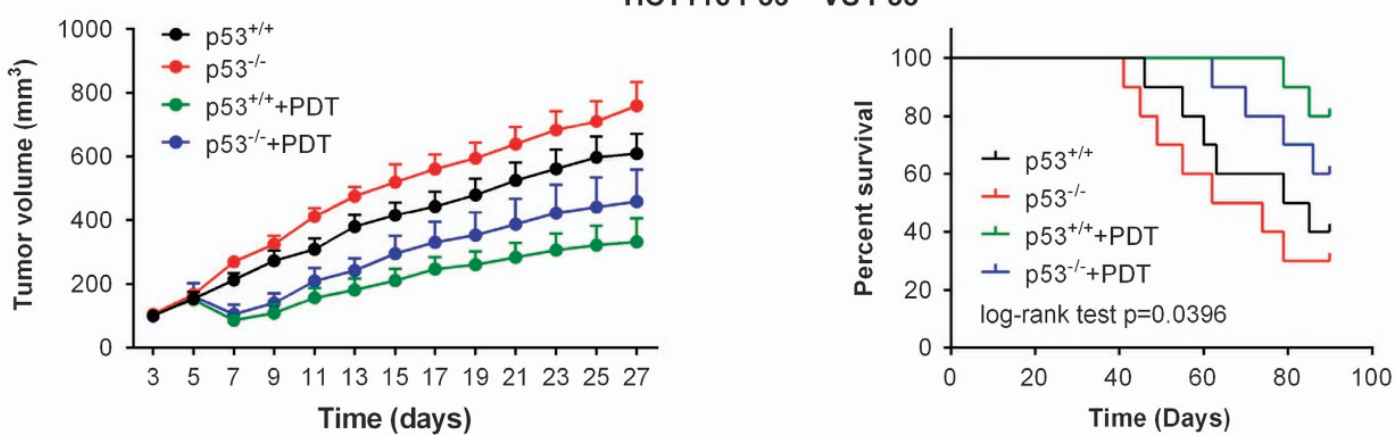
Figure 1 The effect of PDT on cell viability, tumor size and survival percentage. (a) The viability of all CRC cells in response to PDT treatment in a concentration-dependent manner was determined by using CCK-8 assays. (b) The p53 protein levels in shRNA NC- or p53wt shRNA-transfected HCT116 cells and p53 ${ }^{+/ /} / \mathrm{p} 53^{-1-} \mathrm{HCT} 116$ cells were determined using western blotting assays. (b) The viability of $p 53^{\text {wt }} \mathrm{RKO}$ and $p 53^{\text {mut }} \mathrm{HT} 29$ cells was determined at 24 and $48 \mathrm{~h}$ in the presence or absence of PDT treatment by using CCK-8 assays. (c) HCT116 cells were transfected with shRNA NC or p53wt shRNA. Then the cell viability was determined at 24 and $48 \mathrm{~h}$ in the presence or absence of

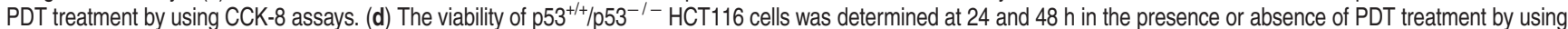
CCK-8 assays. (e) Tumor volumes of tumors derived from p5 $3^{\text {wt }}$ RKO or p53 ${ }^{\text {mut }} \mathrm{HT} 29$ cells in the absence or presence of PDT treatment were determined every 2 days from day 3 to day 27. The survival analysis was performed to analyze the survival percentage of the mice in the indicated groups. (f) Similar assays were performed to analyze $\mathrm{p} 53^{+/ /} / \mathrm{p} 53^{-/-}$ HCT116 cell-derived tumor mice. The data are presented as mean \pm S.D. of three independent experiments. ${ }^{*} P<0.01,48 \mathrm{~h}$ group versus $24 \mathrm{~h}$ group; \#P<0.05, \#\#P<0.01, HT29 group versus RKO group or p53wt shRNA group versus shRNA NC group or $p 53^{-1-}$ HCT116 group versus $p 53^{+/+}$HCT116 group; \&\&P<0.01, PDT (+) group versus PDT $(-)$ group

a

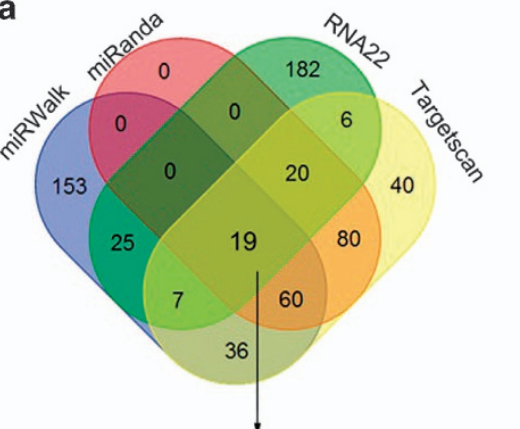

hsa-miR-140-5p hsa-miR-617

hsa-miR-650 hsa-miR-30c-3p

b RKO vs HT29

hsa-miR-3619-5p hsa-miR-3714

hsa-miR-30b-3p hsa-miR-940

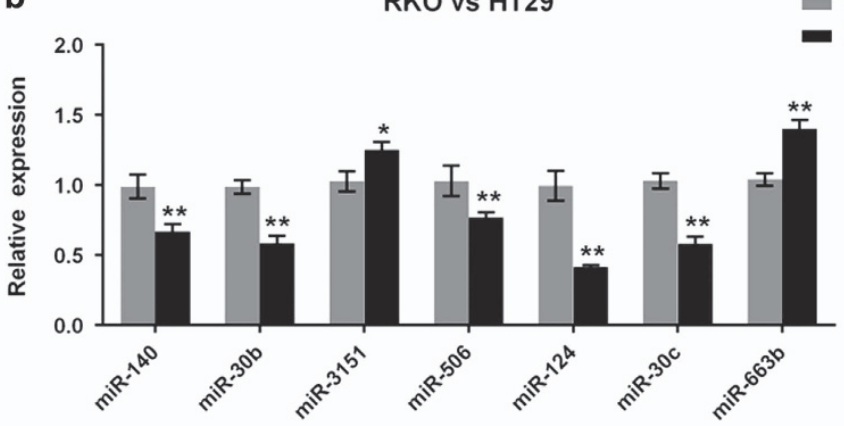

hsa-miR-3689a-3p hsa-miR-612

hsa-miR-3151-5p hsa-miR-342-5p

hsa-miR-506-3p hsa-miR-663b

hsa-miR-3622b-5p hsa-miR-1275

hsa-miR-124-3p hsa-miR-3919

hsa-miR-4290
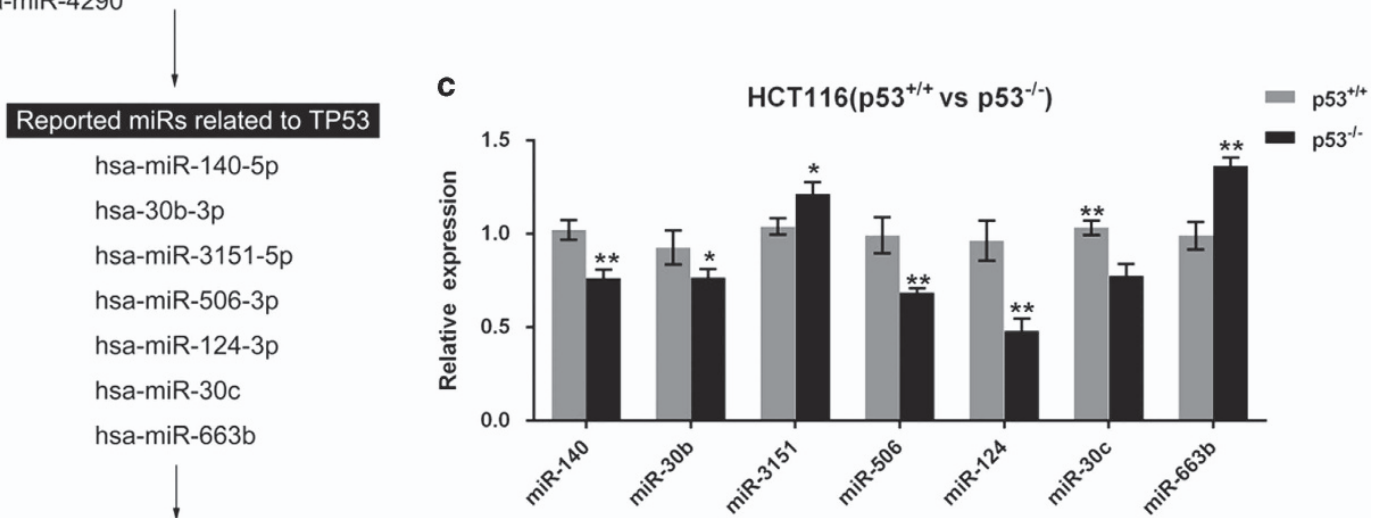

Figure 2 Screening and verification of candidate miRNAs for p53. (a) Online tools, including miRWalk, miRanda, RNA22 and Targetscan, were used to screen out candidate miRNAs that could be regulated by p53. (b) The expression levels of candidate miRNAs were determined in RKO and HT29 cells by using real-time PCR assays. (c) The

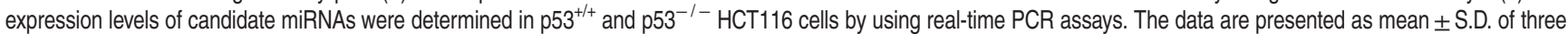
independent experiments. ${ }^{*} P<0.05,{ }^{*} P<0.01$

response to PDT treatment. miR-124 mimics or miR-124 inhibitor was transfected into RKO, $\mathrm{HT} 29,{\mathrm{p} 53^{+/+}}$and $\mathrm{p} 53^{-/-}$ HCT116 cells to achieve miR-124 overexpression or miR-124 inhibition (Figure 4a). Results showed that the viability of p53 ${ }^{\text {wt }}$ CRC cell line RKO in the PDT (+)+miR-124 group was the lowest, whereas the viability of the p53mut CRC cell line HT29 in the PDT $(-)+$ miR-SCR group was the highest (Figure 4b). Similar results were observed in $\mathrm{p} 53^{+/+} /{\mathrm{p} 53^{-/-}}^{-1}$ cells: the viability of $\mathrm{p} 53^{+/+} \mathrm{CRC}$ cell line RKO in the PDT (+) +miR-124 group was the lowest, whereas the viability of 

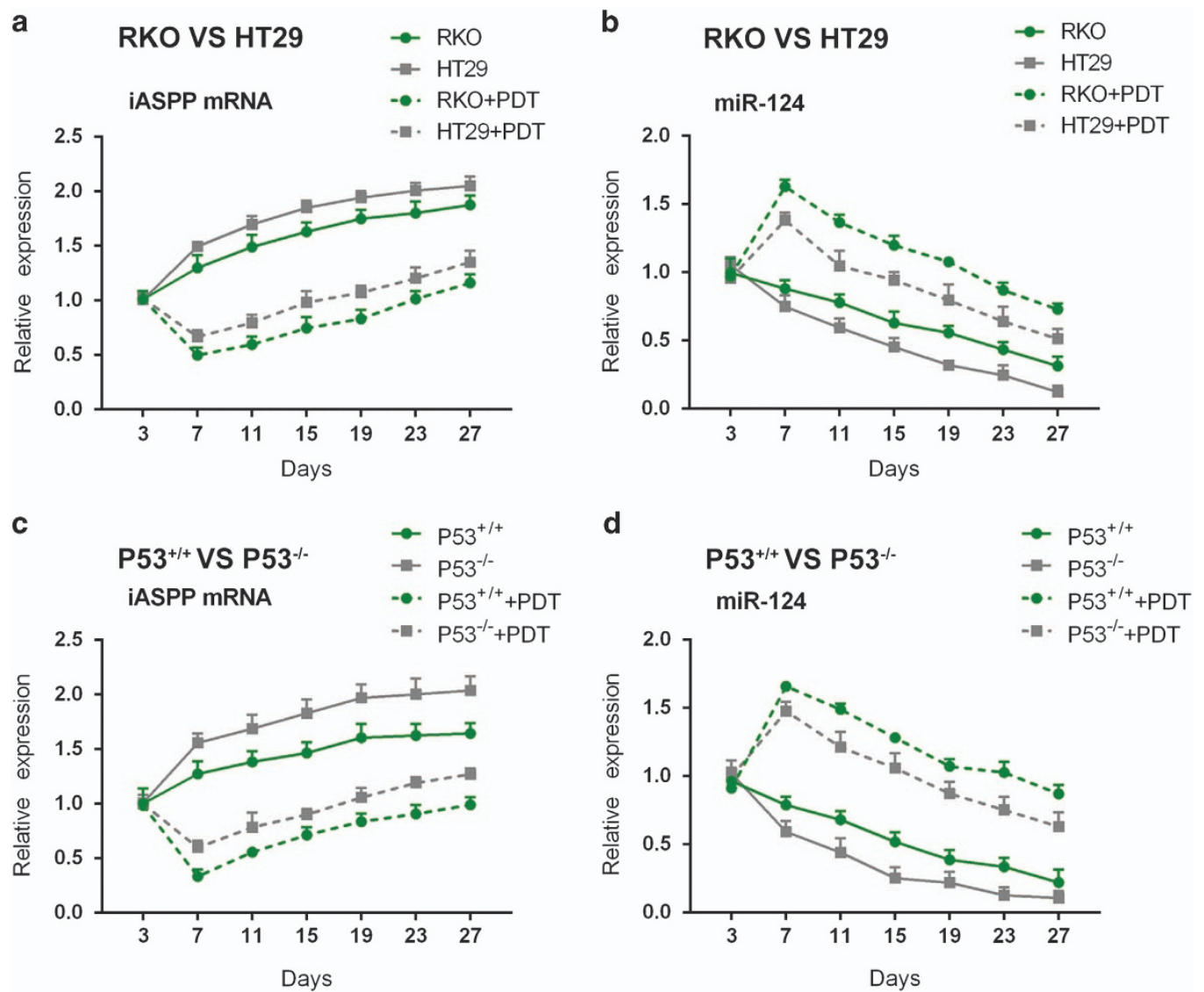

Figure 3 The effect of PDT on miR-124 and iASPP mRNA expression. (a and c) iASPP mRNA expression in HT29-, RKO-, p53 $3^{+/+}$- and p53 $3^{-1-}$ cell-derived tumors in the presence or absence of PDT was determined using real-time PCR on days $3,7,11,15,19,23$ and 27. (b and d) miR-124 expression in HT29-, RKO-, p53 $3^{+/+}$- and p53 ${ }^{-1-}$ cellderived tumors in the presence or absence of PDT was determined using real-time PCR on days 3, 7, 11, 15, 19, 23 and 27. The data are presented as mean \pm S.D. of three independent experiments

p53 $3^{-1}$ CRC cell line HT29 in the PDT $(-)+$ miR-SCR group was the highest (Figure 4c). The data suggested that miR-124 could promote the sensitivity of CRC cells to PDT treatment, so as to promote the inhibitory effect of PDT on CRC cells. Moreover, p53 mutation might reduce miR-124induced sensitivity of CRC to PDT treatment.

Next we investigated the effect of iASPP on the viability of p53 $3^{\text {wt }} / \mathrm{p} 53^{\text {mut }}$ CRC cells in the absence or presence of PDT treatment. PcDNA3.1/iASPP vector was transfected into RKO, HT29, $\mathrm{p}^{+/+}$and $\mathrm{p} 53^{-/-} \mathrm{HCT} 116$ cells to achieve forced iASPP expression. The transfection efficiency was verified by using western blotting assays. Results showed that the viability of both $\mathrm{p} 53^{\mathrm{wt}}$ and $\mathrm{p} 53^{\mathrm{mut}} \mathrm{CRC}$ cell line was significantly upregulated by IASPP overexpression in the PDT (-) group, more strongly promoted in $\mathrm{p} 53^{\text {mut }} \mathrm{CRC}$ cell line. The viability of both $p 53^{\text {wt }}$ and $p 53^{\text {mut }}$ CRC cell line was downregulated by PDT treatment and partially restored by iASPP overexpression. Among the two CRC cell lines, the viability of $p 53^{\text {wt }} C R C$ cells was more strongly suppressed by PDT treatment, while the viability of $p 53^{\text {mut }}$ CRC cells was more strongly restored by iASPP overexpression (Figure 4d). Similar results were observed in $\mathrm{p} 53^{+/+} / \mathrm{p} 53^{-/-}$HCT116 cells:

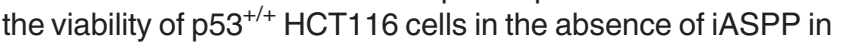
the PDT (+) group was the lowest, whereas the viability of p53 ${ }^{-/-}$HCT116 cells in the presence of iASPP in the PDT $(-)$ group was the highest (Figure 4e). The data suggested that iASPP could reduce the sensitivity of CRC cells to PDT treatment, thus reducing the inhibitory effect of PDT on CRC cells. Moreover, p53 mutation or knockout could amplify the effect of iASPP on CRC cells' sensitivity to PDT.

p53 regulates miR-124 expression by binding to its promoter. To investigate the role of miR-124 further in CRC cells, we focused on the mechanism of miR-124 overexpression in these cells. pcDNA3.1/p53 was transfected

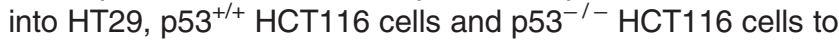
achieve forced p53 expression in the presence or absence of PDT treatment. p53 protein levels were then determined using western blotting assays. As shown in Figure 5a, p53 protein was increased in all p53-transfected cells, compared with that in pcDNA3.1-transfected cells; more importantly, p53 protein levels were higher in the PDT treatment group, compared with those in the non-PDT treatment group. Figure $5 b$ is a schematic diagram of the potential p53binding element in the promoter region of the miR-124 gene predicted by Jaspar database. A mutated binding element was constructed by mutating $13 \mathrm{bp}$ within the binding element. We subcloned the wt- or mut-binding element and 
a

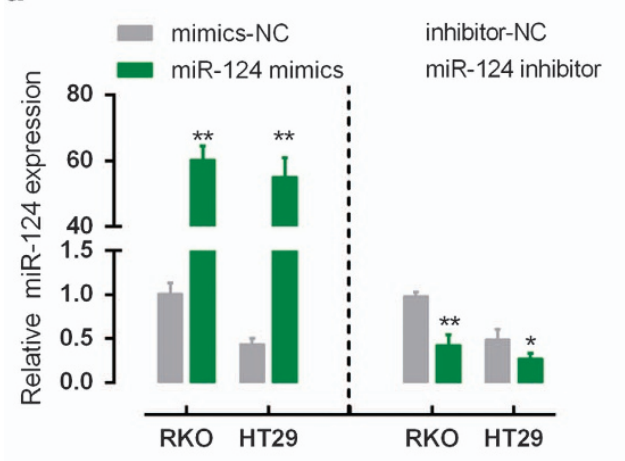

c

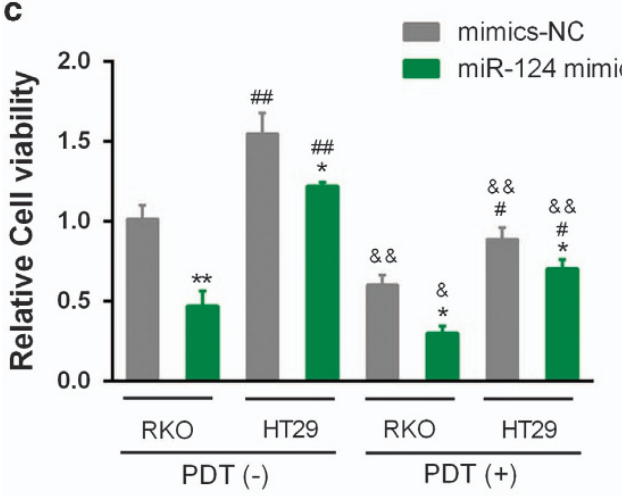

e
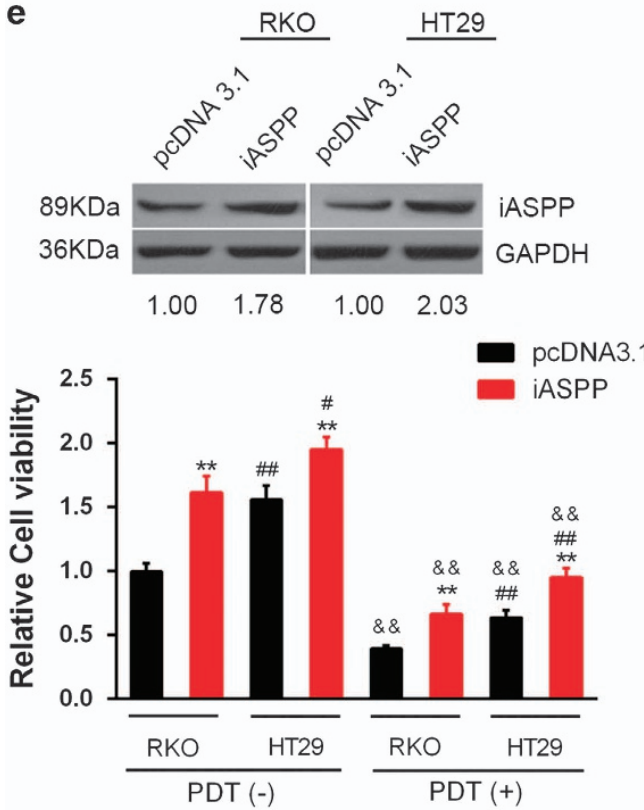

b

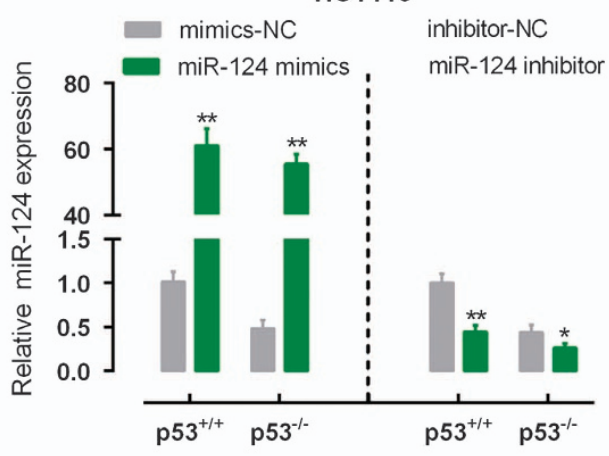

d

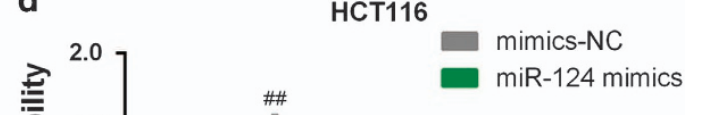

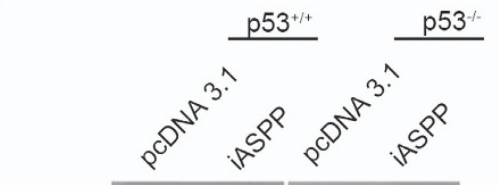

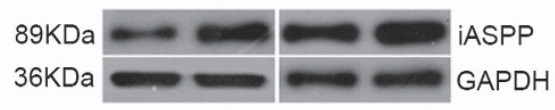

$\begin{array}{llll}1.00 & 2.13 & 1.00 & 2.24\end{array}$

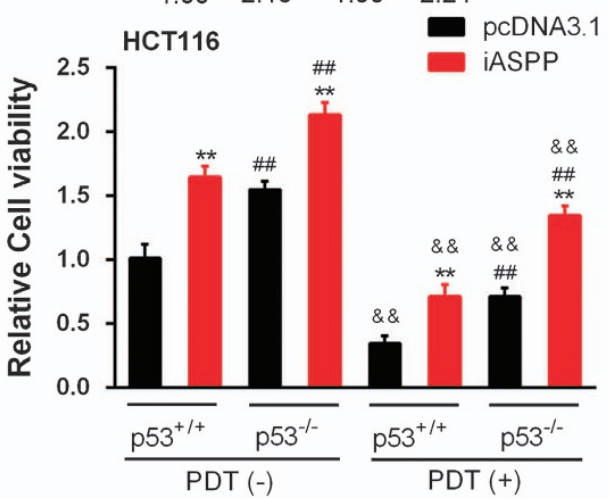

Figure 4 The influence of miR-124 or iASPP on $p 53^{\mathrm{wt}} / \mathrm{p} 53^{\mathrm{mut}}$ and $\mathrm{p} 53^{+/ /} / \mathrm{p} 53^{-1-}$ cells in response to PDT treatment. (a) and (b) miR-124 mimics or miR-124 inhibitor was transfected into RKO $\left(\mathrm{p} 53^{\mathrm{wt}}\right), \mathrm{HT} 29$ ( $\left.\mathrm{p} 53^{\mathrm{mut}}\right), \mathrm{p} 53^{+/+}$or $\mathrm{p} 53^{-1-}$ cells to achieve miR-124 overexpression or miR-124 inhibition. The transfection efficiency was verified by using real-time PCR assays. (c) The viability of p53 ${ }^{\text {wt }}$ CRC cell line RKO and p53 ${ }^{\text {mut }}$ cell line HT 29 transfected with miR-SCR or miR-124 in the absence or presence of PDT was determined by using CCK-8 assays. (d) The viability of $p 53^{+/+}$CRC cell line and $p 53^{-1-}$ cell line transfected with miR-SCR or miR-124 in the absence or presence of PDT was determined by using CCK-8 assays. (e) The viability of p53 ${ }^{\text {wt }} \mathrm{CRC}$ cell line RKO and p53 ${ }^{\text {mut }}$ cell line HT 29 transfected with pcDNA3.1 or pcDNA3.1-iASPP in the absence or presence of PDT was determined by using CCK-8 assays. (f) The viability of $p 53^{+/+} \mathrm{CRC}$ cell line and $p 53^{-/-}$cell line transfected with pcDNA3.1 or pcDNA3.1-iASPP in the absence or presence of PDT was determined by using CCK-8 assays. The data are presented as mean \pm S.D. of three independent experiments. ${ }^{*} P<0.05,{ }^{* *} P<0.01$, miR-124 mimics versus mimics-NC, or iASPP versus pcDNA3.1; \#P<0.05, \#\#P<0.01, HT29 versus RKO, or $\mathrm{p5} 3^{-1-}$ HCT116 versus $\mathrm{p} 53^{+/+}$HCT116; \&P<0.05, \&\&P<0.01, PDT (+) group versus PDT ( - ) group 
a

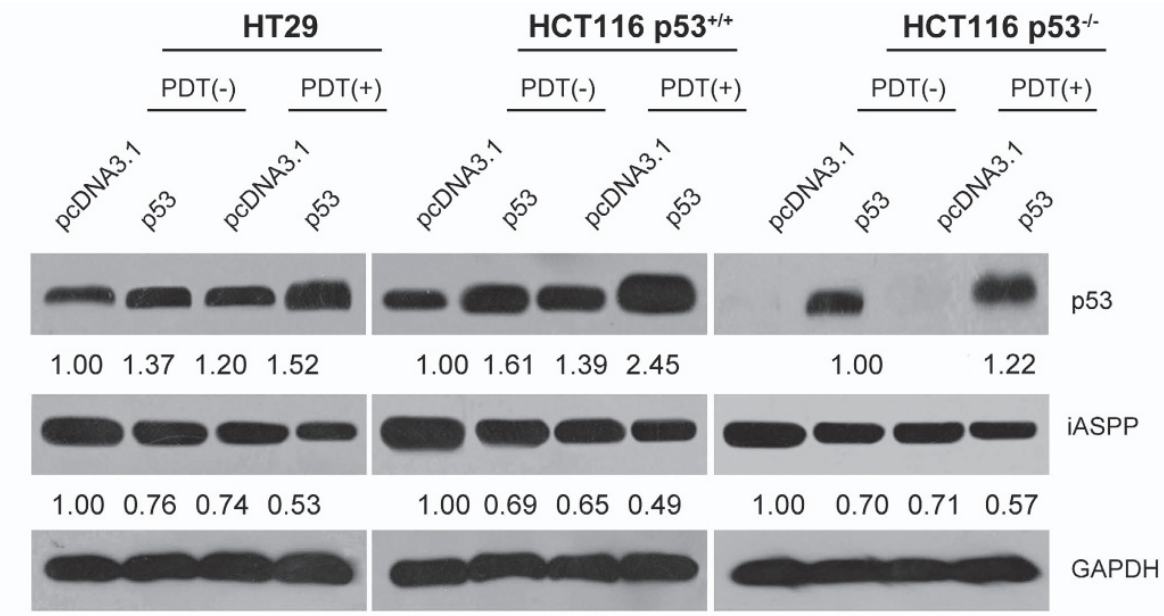

b

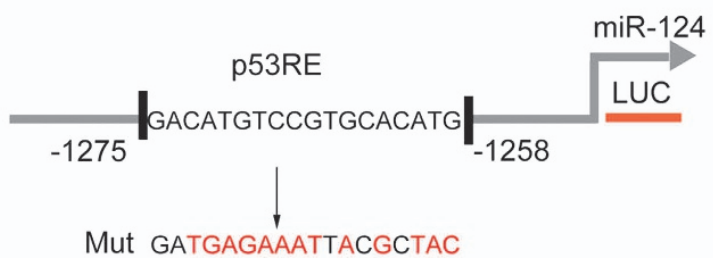

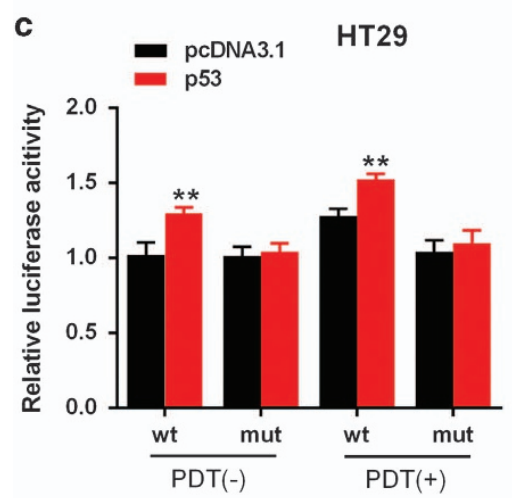

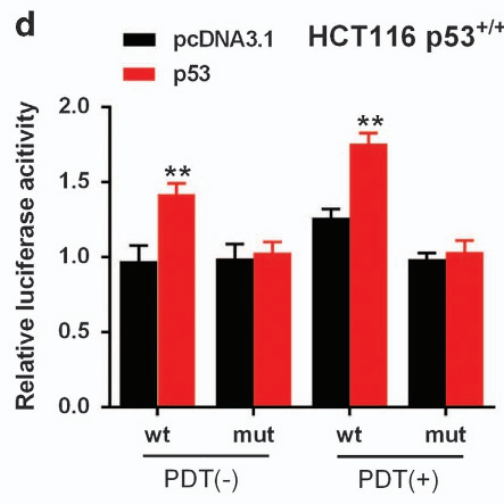$$
\text { f }
$$

HT29

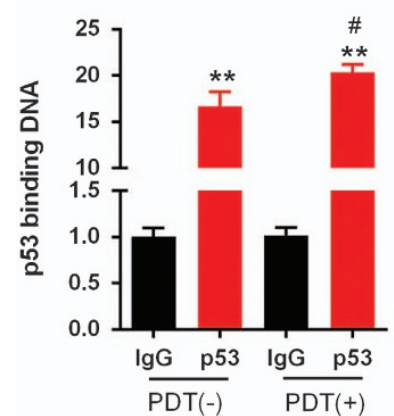

g

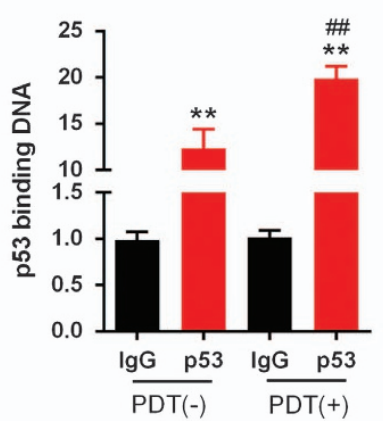

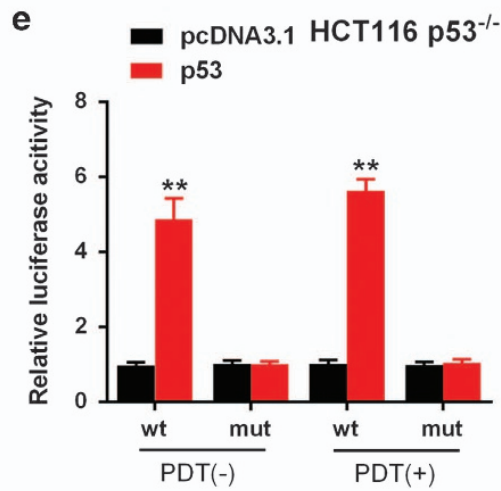

h

HCT116 $\mathrm{p53}^{-/-}$

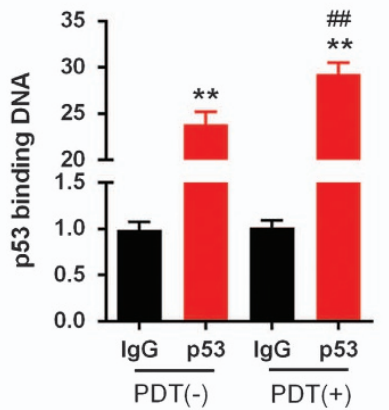

Figure 5 p53 regulates miR-124 expression by binding its promoter. (a) pcDNA3.1/p53 vector was transfected into HT29, p53 ${ }^{+/+} \mathrm{HCT} 116$ cell and p53 $3^{-/-} \mathrm{HCT} 116$ cell to achieve forced p53 expression in the presence or absence of PDT. (b) A schematic diagram of a potential p53 binding element in the promoter region of the miR-124 gene predicted by Jaspar database. A wt-miR-124 promoter luciferase reporter vector and a mut-miR-124 promoter luciferase reporter vector were constructed. (c-e) The indicated luciferase reporter vectors were co-transfected into HT29, p53 ${ }^{+/+}$HCT116 cells and p53 ${ }^{-1-}$ HCT116 cells with pcDNA3.1/p53 vector in the presence or absence of PDT. The luciferase activity was then determined by using dual luciferase assays. $(\mathbf{f}-\mathbf{h})$ The real-time ChIP assay showed that the level of p53 antibody binding to miR-124 promoter was much greater than that of $\lg G$ in the presence or absence of PDT. The data are presented as mean \pm S.D. of three independent experiments. ${ }^{\star \star} P<0.01$, compared with the pcDNA3.1 group; ${ }^{\#} P<0.05,{ }^{\# \#} P<0.01$, compared with the $p 53+P D T(-)$ group 
co-transfected the constructs with pcDNA3.1/p53 luciferase

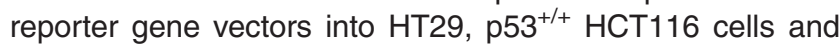
p53 ${ }^{-1-}$ HCT116 cells in the presence or absence of PDT treatment (Figures $5 c-e$ ). As shown in Figures $5 c-e$, p53 significantly promoted the luciferase activity as compared with pcDNA3.1 when co-transfected with wt-binding element either in the presence or absence of PDT treatment; in all cells, the luciferase activity was slightly stronger in the PDT treatment group, compared with that in the non-PDT treatment group, suggesting a PDT-promoted p53 protein level (Figure 5d). When the binding element was mutated, luciferase activity was not changed either in the presence or absence of PDT treatment, compared with that of the pcNDA3.1 (Figures $5 \mathrm{c}-\mathrm{e}$ ). Furthermore, the real-time chromatin immunoprecipitation (ChIP) assay showed that the level of p53 antibody binding to miR-124-binding element in the miR-124 promoter was much greater than that of $\lg G$ in all the three indicated cell lines (Figures $5 f-h$ ), suggesting that p53 might bind to the promoter of miR-124 to activate its expression. Similarly, in all cells, the level of p53 antibody binding to miR-124-binding element in miR-124 promoter was significantly promoted by PDT treatment $(\# P<0.05$, $\# \# P<0.01$ ), compared with that in the absence of PDT, indicating that PDT treatment significantly upregulated p53 protein level (Figures $5 f-h)$.

The correlation of p53, miR-124 and iASPP expression in CRC tissues. Clinic samples containing diverse p53 levels
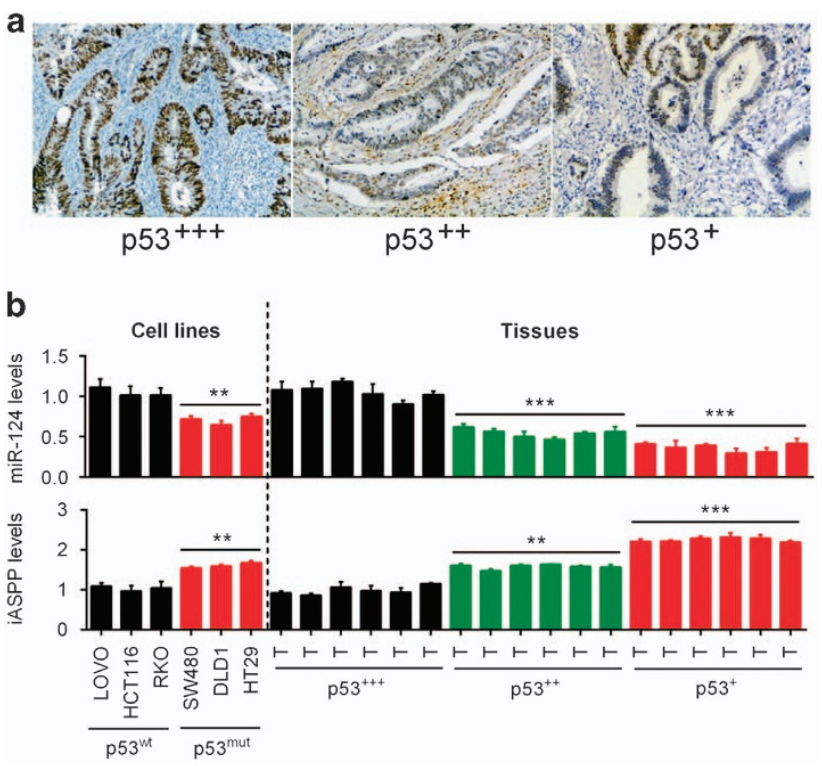

Figure 6 The correlation of p53, miR-124 and iASPP expression in CRC tissues. (a) Clinic samples containing diverse p53 levels have been obtained and the pathological states have been assessed. Results showed that the samples possessing higher p53 content had a better pathological condition. (b) miR-124 expression was upregulated in p53wt cells but downregulated in p53mut cells, and the expression levels were altered in a p53 content-dependent manner; iASPP expression was downregulated in p53wt cells but upregulated in p53mut cells, and the expression levels were altered in a p53 content-dependent manner. The data are presented as mean \pm S.D. of three independent experiments. ${ }^{* *} P<0.01$, ${ }^{* \star *} P<0.005$ have been obtained and the pathological states have been assessed. Results showed that the samples possessing higher p53 content had a better pathological condition (Figure 6a). Our previous study revealed that miR-124 regulates the proliferation of CRC cells by targeting iASPP. ${ }^{14}$ To investigate the effect of mutant p53 on the expression of miR-124 and iASPP, we then determined miR-124 and iASPP expression in $p 53^{\text {wt }}$ cells and $p 53^{\text {mut }}$ cells. Results showed that miR-124 expression was upregulated in $p 53^{\text {wt }}$ cells but downregulated in $p 53^{\text {mut }}$ cells, and the expression levels were altered in a p53 content-dependent manner in tumor tissues; iASPP expression was downregulated in $p 53^{\mathrm{wt}}$ cells but upregulated in $\mathrm{p} 53^{\mathrm{mut}}$ cells, and the expression levels were altered in a p53 contentdependent manner in tumor tissues (Figure 6b).

Schematic diagram of the role of p53 mutation or knockout in PDT treatment. In the present study, we revealed that p53 promoted miR-124 expression to inhibit iASPP expression, so as to amplify the inhibitory effect of PDT on CRC cell proliferation; after p53 mutantion or knockout, miR-124 expression was downregulated while iASPP expression was upregulated, so that the inhibitory effect of PDT on CRC cell proliferation was reduced (Figure 7).

\section{Discussion}

In recent years, PDT has been more and more applied clinically, the functional mechanism of which relies mainly on the generation of an active form of oxygen that may compromise cell viability and accelerate apoptosis. ${ }^{25-27}$ As a sensor of cellular stress, p53 is a relevant messenger of cell death signaling in PDT. The significant role of p53 in response to PDT has been reported for several clinically approved photosensitizers. ${ }^{28,29}$ PDT induces an apoptotic pathway involving p53 and inactivates survival signal in human umbilical vein endothelial cells. ${ }^{30}$ Therefore, p53 mutation or deletion could weaken the sensitivity of cells to PDT. p53

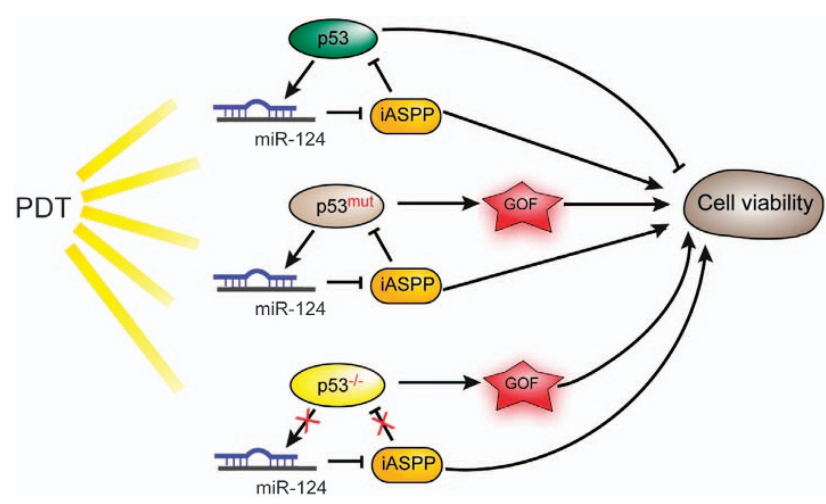

Figure 7 Schematic diagram of the role of p53 mutation or knockout in PDT treatment. In the present study, we revealed that p53 promoted miR-124 expression to inhibit iASPP expression, so as to amplify the inhibitory effect of PDT on CRC cell proliferation; after p53 mutation or knockout, miR-124 expression was downregulated while the iASPP expression was upregulated, so that the inhibitory effect of PDT on $\mathrm{CRC}$ cell proliferation was reduced 
mutation is commonly seen in the process of tumorigenesis and remains a tough obstacle to clinical treatment of malignancies. Most cases resistant to chemotherapy or radiotherapy display some extent of p53 abnormality. ${ }^{31-33}$ Mutant-type p53 cells were found to be significantly less sensitive to photofrin-mediated PDT. ${ }^{13}$ Wild-type p53 gene transfer into mutated p53 HT29 cells improves sensitivity to PDT via induction of apoptosis. ${ }^{34}$ p53 has been found involved in the above process as the mutation of p53 may influence the efficacy of PDT and make cancer cells less photosensitive to that PDT ignition. ${ }^{35,36}$ In the present study, we observed that in p53-mutant or -deleted cells, p53 protein levels were significantly reduced, and the inhibitory effect of PDT on cell viability was significantly weakened, compared with wild-type

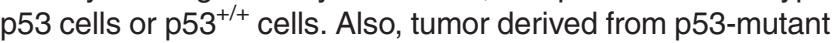
or -deleted cells obtained continuously increased tumor size and caused shorter survival time. These findings revealed the major role of p53 mutation or deletion in PDT process; the killing effect of PDT on CRC cell might be p53 dependent.

According to previous studies, iASPP is a key inhibitor of the tumor-suppressor p53 in various cancers, including prostate cancer, ${ }^{37}$ liver cancer, ${ }^{38}$ lung cancer ${ }^{39}$ and glioma. ${ }^{40}$ Dong et al. ${ }^{41}$ summarize the oncogenic roles of iASPP in promoting proliferation, invasion, drug or radiation resistance and metastasis. The inhibition of iASPP phosphorylation with small molecules induces p53-dependent apoptosis and growth suppression. ${ }^{41}$ The role of iASPP in mediating p53induced apoptosis and suppression of cell proliferation inspired us to validate its detailed function in PDT on CRC cells. We observed that exogenous iASPP expression increased the cell viability of $\mathrm{CRC}$ cell lines and attenuated the inhibitory effect of PDTon CRC cell lines. These suggested that iASPP might mediate p53-independent pathway in PDT process; in other words, as we have demonstrated that the killing effect of PDT on CRC cell might be p53 dependent, we further figure out that iASPP can suppress p53-induced cancer cell apoptosis under PDT treatment through inhibiting p53 expression, thus attenuating the killing effect of PDT on CRC cell.

Human cancer is associated with changes in miRNA expression. The pattern of miRNA expression varies dramatically across tumor types, and miRNA profiles reflect the developmental lineage and differentiation state of a tumor. ${ }^{42}$ miRNA is also likely to have critical roles in the PDT process. ${ }^{43}$ Hypoxia induced by PDT induces miR-210 expression, followed by an increased expression of both VEGF and miR-296. ${ }^{44}$ Bach et al. ${ }^{45}$ identified eight miRNAs that were significantly differentially expressed $5 \mathrm{~h}$ after PDT, compared with baseline levels, and an up to 15-fold transient upregulation of miR-634, -1246 and -1290 relative to their basal levels. Given the major role of p53 in PDT process, we screened out several candidate miRNAs that could be regulated by p53 and verified the expression levels of these miRNAs in $p 53^{\mathrm{wt}}$, $\mathrm{p} 53^{\mathrm{mut}}, \mathrm{p} 53^{+/+}$and $\mathrm{p} 53^{-/-}$cells. Among all of the candidate miRNAs, miR-124 showed to be significantly downregulated in p53 ${ }^{\text {mut }}$ and $\mathrm{p} 53^{-1-}$ cells. In our previous study, we revealed that miR-124 could inhibit iASPP by direct targeting to suppress $\mathrm{CRC}$ cell proliferation so as to affect the course of CRC. ${ }^{14}$ Here we validated their functional roles in PDT on CRC cells. For the first time, we demonstrated the amplificatory effect of miR-124 on PDT suppressing CRC cell viability, which could be partially abolished by p53 mutation or deletion; on the contrary, IASPP suppressed the inhibitory effect of PDT on CRC cell viability, which could be amplified by p53 mutation or deletion. On day 7 after PDT, the expression level of miR-124 presented a peak value, while iASPP expression presented a valley value at the same time, which was consistent with the tumor size alternation trend in response to PDT. These all suggested the important role of miR-124/iASPP in PDT process.

The biological effects of $p 53$ are largely due to its function as a transcriptional regulator. ${ }^{46}$ p53 induces the expression and/ or maturation of several miRNAs, which leads to the repression of critical effector proteins. The frequent genetic and epigenetic alterations of p53-regulated miRNAs in tumors indicate that they have an important role in cancer initiation and/or progression. ${ }^{47}$ Jeong et al. ${ }^{23}$ characterized miR-124 promoter region and identified a functional p53-binding site. In agreement with this finding, endogenous or ectopic expression of wild-type p53 increased miR-124 levels. ${ }^{23}$ Interestingly, here we found that $\mathrm{p} 53$ binds to the promoter of miR-124 to promote its expression in the presence or absence of PDT and subsequently affect the expression of miR-124 downstream target gene, so as to form a regulation loop in the wild-type p53 cells. In p53-mutant or -deleted cells, this binding no longer worked to promote miR-124 expression, and iASPP expression increased, which finally resulted in attenuated killing effect of PDT on CRC cells and promoted CRC cell viability.

All in all, the interactive modulation among miR and IASPP in p53-mutant or -deleted cells may serve as a crucial pathway, which mediates therapy resistance when p53 is mutated or deleted, in the process of PDT treatment of CRC. These findings may well be meaningful in bringing up the efficacy and optimizing the strategy of PDT. Nevertheless, considering the firm association between p53 mutation and tumor metastasis and resistance to chemotherapy or radiotherapy, the newly found miR-iASPP interaction may well enlighten us with novel directions in dealing with these problems in the near future.

\section{Materials and Methods}

Photosensitizers. 5,10,15,20-tetrakis(pentafluorophenyl)-2,3-(methano[Nmethyl] iminomethano])chlorin) (H2TFPC) and H2TFPCSGlc (Figure 1a) were synthesized and provided by the laboratory of the Kyoto University (Kyoto, Japan) and Okayama University of Science (Okayama, Japan). They contain no isomers, based on $1 \mathrm{H}$ NMRand 19F-NMR measurements.

Cell culture. HCT116, LoVo, RKO, HT29, DLD1 and SW480 cell lines have been characterized in detail and was provided by ATCC (Manassas, VA, USA). These were cultured in Eagle minimum essential medium (Wako Pure Chemical Industries Co. Ltd., Wako, Japan) supplemented with 10\% FBS and 1\% ampicillin and streptomycin under $5 \% \mathrm{CO}_{2}$ at $37^{\circ} \mathrm{C}$.

PDT and phototoxicity experiments. MTHPC was obtained from Biolitec AG (Jena, Germany) at a concentration of $5.88 \mathrm{mM}(4 \mathrm{mg} / \mathrm{ml}$ diluted with the ethanol/propylene glycol solvent to a working stock concentration of $0.588 \mathrm{mM}$ $(400 \mu \mathrm{g} / \mathrm{ml}))$ and stored at $4{ }^{\circ} \mathrm{C}$ in the dark. Porfimersodium was obtained from Seehof Laboratorium (Wesselburenerkoog, Germany) at a concentration of $9.96 \mathrm{mg} / \mathrm{ml}$ (corresponding to $16.67 \mathrm{mM}$ based on a nominal molecular weight of $600 \mathrm{~g} / \mathrm{mol}$ ) and stored at $4{ }^{\circ} \mathrm{C}$ in the dark. Resazurin sodium salt was obtained from Sigma-Aldrich (Vienna, Austria). Cells cultured in 96-well microplates (black walls, clear bottom) were washed once with $100 \mu \mathrm{l}$ sf-DMEM and incubated with $0.588 \mu \mathrm{M}$ $(400 \mathrm{ng} / \mathrm{ml}) \mathrm{mTHPC}$ and $1.2 \mu \mathrm{g} / \mathrm{ml}(2 \mu \mathrm{M})$ porfimer sodium, respectively, again 
using $100 \mu \mathrm{l}$ sf-DMEM. Subsequent to $20 \mathrm{~h}$ incubation, photosensitized cells were illuminated from below the microplates using LED arrays as light sources. ${ }^{48} 660 \mathrm{~nm}$ $\left(0.65 \mathrm{~J} / \mathrm{cm}^{2}\right)$ and $624 \mathrm{~nm}\left(4.30 \mathrm{~J} / \mathrm{cm}^{2}\right)$ dominant wavelength with a current of $5 \mathrm{~A}$ were employed for 3 or $7 \mathrm{~min}$ (for $\mathrm{mTHPC}$ and porfimer sodium, respectively, described in). Directly after illumination and $24 \mathrm{~h}$ afterwards, the cellular viability was assessed by adding $20 \mu \mathrm{l} 2.5 \mathrm{mM}$ resazurinin PBS to each well, incubating for $2 \mathrm{~h}$ at $37^{\circ} \mathrm{C}$ and measured using the Infinite M200 microplate reader (Tecan, Grödig, Austria) at $\lambda_{\mathrm{ex}}=535 \mathrm{~nm}$ and $\lambda_{\mathrm{em}}=588 \mathrm{~nm}$. Similar to other viability assays (CCK-8), the fluorimetric resazurin method indicates the proportion of metabolically active (viable) cells. For the current data set (mTHPC and porfimer), the obtained values were corrected for blank wells and related to the baseline viability $(0 \mathrm{~h}$ values); the second data set (mTHPC, adopted from an earlier publication) was related to untreated controls measured at $24 \mathrm{~h}$ after illumination. For correlation of $\mathrm{miR}$ expression data with the phototoxicity after correction by the cell-dependent uptake of the PS, the fluorimetry uptake values were adopted from the mentioned earlier study. For the current set of mTHPC- and porfimer sodium-based phototoxicity, the cellular uptake (corrected by total protein) was measured by fluorimertry as described previously.

Mouse experiments. HT29, RKO, $\mathrm{p} 53^{+/+} \mathrm{HCT} 116$ and $\mathrm{p} 53^{-/-} \mathrm{HCT} 116$ cell lines were used for the injection of the mice, 10 mice in each group. Cells $\left(5 \times 10^{5}\right.$ cells per animal) were suspended in $100 \mu \mathrm{l}$ of serum-free DMEM mixed with $100 \mu \mathrm{l}$ of $10 \%$ Matrigel (BD, Franklin Lakes, NJ, USA) and injected subcutaneously into 58-week-old female BALB/c nude mice. Tumor size was measured every 2 days from day 3 to day 27 in the absence or presence of PDT treatment. Animals were humanely killed depending on tumor volume. Expression levels of miR-124 and iASPP was determined in tumors that were derived from the indicated cells by injection on days $3,7,13,20$ and 27. The tumor was snap-frozen, and RNA was extracted for measurement of miR-124 and iASPP levels by specific Taqman probes. The methods were carried out in accordance with the relevant guidelines and regulations. Animal protocols were approved by the Ethics Committee of the Second Xiangya Hospital, Central South University.

RNA extraction and SYBR Green quantitative PCR analysis. Total RNA was extracted from CRC cells using TRIzol reagent (Invitrogen, Carlsbad, CA, USA). The expression levels of miRNAs were detected using the Hairpin-it miRNAs qPCR Kit (Genepharma, Shanghai, China). The expression of RNU6B served as an endogenous control. IASPP expression was measured using a SYBR Green APCR assay (Takara, Dalian, China). The data were processed according to the $2^{-\Delta \Delta C T}$ method; the relative expression of miR-124 was calculated with the formula, $2^{- \text {(CTmiRNA - CTRNU6B) }}$. The primers are shown in Supplementary Table 1.

CCK-8 cell proliferation assay. Cell proliferation rates were measured using the CCK-8 (Beyotime, Hangzhou, China) methods. Approximately $0.5 \times 10^{4}$ cells were seeded in each 96-well plate for $24 \mathrm{~h}$, after which they were transfected with the indicated miRNA or siRNA and further incubated for 24 or $48 \mathrm{~h}$. CCK-8 reagent $(10 \mu l)$ was added to each well $1 \mathrm{~h}$ before the end point of each incubation period. The $\mathrm{OD}_{450}$ value was determined for each well using a microplate reader. The relative cell viability was normalized to the value of RKO in the absence of PDT $24 \mathrm{~h}$ after transfection.

Luciferase reporter assay. Cells were transfected with miR-124 and pGL3 luciferase reporter constructs harboring the miR-124 target sequence. After $24 \mathrm{~h}$, the activities of firefly luciferase and Renilla luciferase were measured in the cell lysates using a Dual-Luciferase Assay System (Promega, Madison, WI, USA). For the luciferase transcription reporter assay, miR-124 gene promoter sequences (WT or site deletion) were cloned into the promoter region of the pGL3-Basic vector, and luciferase activity was measured as described above.

Western blotting analysis. The protein levels of iASPP and p53 in CRC cells were detected by performing immunoblotting. We lysed cultured or transfected cells in RIPA buffer with 1\% PMSF and loaded protein onto a SDS-PAGE minigel and transferred them onto PVDF membrane. After probing with the following antibodies: iASPP (ab115605, Abcam, Cambridge, MA, USA), p53 (ab1431, Abcam) and GAPDH (ab9484, Abcam) at $4{ }^{\circ} \mathrm{C}$ overnight, the blots were subsequently incubated with HRP-conjugated secondary antibody $(1: 5000)$. ECL substrates was used to visualize signals (Millipore, Danvers, MA, USA). GAPDH was used as an endogenous protein for normalization.
Chromatin immunoprecipitation. Briefly, the treated cells were crosslinked with $1 \%$ formaldehyde, sheared to an average size of 400 bp DNA and immunoprecipitated using antibodies against p53 (anti-p53, clone D0-7, SigmaAldrich). The ChIP-PCR primers were designed to amplify the promoter regions containing putative $\mathrm{p} 53$-binding sites within $\mathrm{miR}-124$, as previously described (MIR124-p53BS-F and MIR155-p53BS-R are used in the ChIP assay, shown in Supplementary Table S1). A positive control antibody (RNA polymerase II) and a negative control non-immune IgG were used to demonstrate the efficacy of the kit reagents (Epigentek Group Inc., Framingdale, NY, USA, P-2025-48). The immunoprecipitated DNA was subsequently cleaned, released and eluted. The eluted DNA was used for downstream applications, such as ChIP-PCR. The foldenrichment (FE) was calculated as the ratio of the amplification efficiency of the ChIP sample to that of the non-immune IgG. The amplification efficiency of RNA Polymerase II was used as a positive control. FE $\%=2$ (IgG CT-Sample CT) $\times 100 \%$.

Immunohistochemistry. Immunohistochemical $(\mathrm{IHC})$ profile of the tumor was assessed by subjecting one section each from a block to p53 immunostain. IHC was performed on $4 \mu \mathrm{m}$-thick sections from $10 \%$ formalin-fixed paraffin-embedded specimens, according to the streptoavidin-biotin immunoperoxidase technique (Dako-cytomation, Santa Clara, CA, USA). Multiple slides were evaluated, and ideal section was used for $\mathrm{IHC}$ staining.

These sections were reviewed by three blind-folded pathologists; strong brown nuclear immunoreactivity was considered as positive staining; a semiquantitative scoring system was employed to assess the level of p53 reactivity: 0 - was assigned when no staining was observed, 1 - when $<10 \%$ of tumor cell nuclei were reactive, 2 - when $>10 \%$, but $<33 \%$ of the nuclei stained, and $3-$ if $>33 \%$ of nuclei were positive. ${ }^{49-51}$ Herein, a score of $0-1$ was defined as p53+, 2 was defined as p53++, 3 was defined as $\mathrm{p} 53+++$.

Statistical analyses. Data from three independent experiments were expressed as mean \pm S.D. and processed using the SPSS17.0 statistical software (IBM, Armonk, NY, USA). Differences between two groups were compared using Student's paired test. Differences among the groups in the above assays were estimated using one-way ANOVA. A $P$-value $<0.05$ was considered significant.

\section{Conflict of Interest}

The authors declare no conflict of interest.

Acknowledgements. This study was supported by the grants from the National Nature Science Foundation of China (No. 81773293 and No. 81402536), Huxiang Youth Talent Program (2016RS3033) and the Science and Technology Plan Fund in Hunan Province, P.R. China (2014WK2016, 2013FJ6053, 2017JJ2410 and 2015JJ4083).

\section{Author contributions}

$\mathrm{KL}$ : main writer of the article, project leader, cell culture operation, data processing and statistical analysis, and figure preparing. SL: mouse experiments and figure preparing. HZ: photodynamic therapy and phototoxicity experiments. DL: figure preparing. LX: RNA extraction and SYBR Green quantitative PCR analysis. ZL: CCK-8 cell proliferation assay. NZ: luciferase reporter assay and chromatin immunoprecipitation (ChIP). HY: experimental guidance and data verification. YL: experimental guidance and data verification.

\section{Publisher's Note}

Springer Nature remains neutral with regard to jurisdictional claims in published maps and institutional affiliations.

1. Khan AM, Pipkin M, Mozayyan S, Hwang D, Yasufuku K. Severe acute airway obstruction and respiratory failure with fibrous plug following photodynamic therapy (PDT): indication for early bronchoscopy and debridement. Photodiagnosis Photodyn Ther 2014; 11: 254-258.

2. Lee PK, Kloser A. Current methods for photodynamic therapy in the US: comparison of MAL PDT and ALA/PDT. J Drugs Dermatol 2013; 12: 925-930.

3. Master AM, Rodriguez ME, Kenney ME, Oleinick NL, Gupta AS. Delivery of the photosensitizer Pc 4 in PEG-PCL micelles for in vitro PDT studies. J Pharm Sci 2010; 99 : 2386-2398. 
4. Weyergang A, Selbo PK, Berg K. Sustained ERK [corrected] inhibition by EGFR targeting therapies is a predictive factor for synergistic cytotoxicity with PDT as neoadjuvant therapy. Biochim Biophys Acta 2013; 1830: 2659-2670.

5. Gary-Bobo M, Hocine O, Brevet D, Maynadier M, Raehm L, Richeter S et al. Cancer therapy improvement with mesoporous silica nanoparticles combining targeting, drug delivery and PDT. Int J Pharm 2012; 423: 509-515.

6. Poyer F, Thomas CD, Garcia G, Croisy A, Carrez D, Maillard P et al. PDT induced bystander effect on human xenografted colorectal tumors as evidenced by sodium MRI. Photodiagnosis Photodyn Ther 2012; 9: 303-309.

7. Fujita Y, Kato I, Iwai S, Ono K, Suzuki M, Sakurai Y et al. Role of p53 mutation in the effect of boron neutron capture therapy on oral squamous cell carcinoma. Radiat Oncol 2009; 4: 63.

8. Soussi T, Lozano G. p53 mutation heterogeneity in cancer. Biochem Biophys Res Commun 2005; 331: 834-842.

9. Elledge RM, Lock-Lim S, Allred DC, Hilsenbeck SG, Cordner L. p53 mutation and tamoxifen resistance in breast cancer. Clin Cancer Res 1995; 1: 1203-1208.

10. Bond CE, Umapathy A, Ramsnes I, Greco SA, Zhen Zhao Z, Mallitt KA et al. p53 mutation is common in microsatellite stable, BRAF mutant colorectal cancers. Int J Cancer 2012; 130: $1567-1576$.

11. Xu W, Cheng Y, Shen XF. A study on the mutation of P53 and K-ras gene in colorectal adenomas and colorectal carcinomas. Sichuan Da Xue Xue Bao Yi Xue Ban 2012; 43: $821-826$.

12. Heinzelmann-Schwarz V, Fedier A, Hornung $R$, Walt $H$, Haller U, Fink D. Role of p53 and ATM in photodynamic therapy-induced apoptosis. Lasers Surg Med 2003; 33: 182-189.

13. Fisher AM, Rucker N, Wong S, Gomer CJ. Differential photosensitivity in wild-type and mutant p53 human colon carcinoma cell lines. J Photochem Photobiol B 1998; 42: 104-107.

14. Liu K, Zhao H, Yao H, Lei S, Lei Z, Li T et al. MicroRNA-124 regulates the proliferation of colorectal cancer cells by targeting iASPP. Biomed Res Int 2013; 2013: 867537.

15. Kim S, An SS. Role of p53 isoforms and aggregations in cancer. Medicine (Baltimore) 2016; 95: e3993.

16. Zhou L, Xu Z, Ren X, Chen K, Xin S. MicroRNA-124 (MiR-124) inhibits cell proliferation, metastasis and invasion in colorectal cancer by downregulating Rho-associated protein kinase 1 (ROCK1). Cell Physiol Biochem 2016; 38: 1785-1795.

17. Zhang J, Lu Y, Yue X, Li H, Luo X, Wang Y et al. MiR-124 suppresses growth of human colorectal cancer by inhibiting STAT3. PLOS ONE 2013; 8: e70300.

18. Donzelli S, Strano S, Blandino G. microRNAs: short non-coding bullets of gain of function mutant p53 proteins. Oncoscience 2014; 1: 427-433.

19. Liang S, Gong X, Zhang G, Huang G, Lu Y, Li Y. MicroRNA-140 regulates cell growth and invasion in pancreatic duct adenocarcinoma by targeting iASPP. Acta Biochim Biophys Sin (Shanghai) 2016; 48: 174-181

20. Li L, Wang B. Overexpression of microRNA-30b improves adenovirus-mediated p53 cancer gene therapy for laryngeal carcinoma. Int J Mol Sci 2014; 15: 19729-19740.

21. Deshpande SD, Putta S, Wang M, Lai JY, Bitzer M, Nelson RG et al. Transforming growth factor-beta-induced cross talk between p53 and a microRNA in the pathogenesis of diabetic nephropathy. Diabetes 2013; 62: 3151-3162.

22. Yin $M$, Ren $X$, Zhang X, Luo Y, Wang G, Huang $\mathrm{K}$ et al. Selective killing of lung cancer cells by miRNA-506 molecule through inhibiting NF-kappaB p65 to evoke reactive oxygen species generation and p53 activation. Oncogene 2015; 34: 691-703.

23. Jeong D, Kim J, Nam J, Sun H, Lee YH, Lee TJ et al. MicroRNA-124 links p53 to the NFkappaB pathway in B-cell lymphomas. Leukemia 2015; 29: 1868-1874.

24. Raut SK, Singh GB, Rastogi B, Saikia UN, Mittal A, Dogra N et al. miR-30c and miR-181a synergistically modulate p53-p21 pathway in diabetes induced cardiac hypertrophy. Mol Cell Biochem 2016; 417: 191-203.

25. Nakajima N, Kawashima N. A basic study on hypericin-PDT in vitro. Photodiagnosis Photodyn Ther 2012; 9: 196-203.

26. Qiao L, Mei Z, Yang Z, Li X, Cai H, Liu W. ALA-PDT inhibits proliferation and promotes apoptosis of SCC cells through STAT3 signal pathway. Photodiagnosis Photodyn Ther 2016; 14: $66-73$.

27. Tirapelli LF, Morgueti M, da Cunha Tirapelli DP, Bagnato VS, Ferreira J, Neto FS et al. Apoptosis in glioma cells treated with PDT. Photomed Laser Surg 2011; 29: 305-309.

28. Acedo $P$, Zawacka-Pankau J. p53 family members - important messengers in cell death signaling in photodynamic therapy of cancer? Photochem Photobiol Sci 2015; 14 : 1390-1396.

29. Tseng SJ, Liao ZX, Kao SH, Zeng YF, Huang KY, Li HJ et al. Highly specific in vivo gene delivery for p53-mediated apoptosis and genetic photodynamic therapies of tumour. Nat Commun 2015; 6: 6456.

30. Chan WH. Photodynamic treatment induces an apoptotic pathway involving calcium, nitric oxide, p53, p21-activated kinase 2, and c-Jun N-terminal kinase and inactivates survival signal in human umbilical vein endothelial cells. Int J Mol Sci 2011; 12: 1041-1059.
31. Kudo I, Esumi M, Kida A, Ikeda M. p53 mutation, but not in vitro predictor genes of therapeutic efficacy of cisplatin, is clinically relevant in comparing partial and complete responder cases of maxillary squamous cell carcinoma. Oncol Rep 2010; 24: 851-856.

32. Campling BG, El-Deiry WS. Clinical implication of p53 mutation in lung cancer. Mol Biotechnol 2003; 24: 141-156.

33. Iwadate Y, Tagawa M, Fujimoto S, Hirose M, Namba H, Sueyoshi K et al. Mutation of the p53 gene in human astrocytic tumours correlates with increased resistance to DNA-damaging agents but not to anti-microtubule anti-cancer agents. Br J Cancer 1998; 77: 547-551.

34. Barberi-Heyob M, Vedrine PO, Merlin JL, Millon R, Abecassis J, Poupon MF et al. Wild-type p53 gene transfer into mutated p53 HT29 cells improves sensitivity to photodynamic therapy via induction of apoptosis. Int J Oncol 2004; 24: 951-958.

35. Zacal N, Espiritu M, Singh G, Rainbow AJ. Increased BNip3 and decreased mutant p53 in cisplatin-sensitive PDT-resistant HT29 cells. Biochem Biophys Res Commun 2005; 331 648-657.

36. Sherifa G, Saad Zaghloul MA, Elsayed OF, Rueck A, Steiner R, Abdelaziz Al et al. Functional characterization of Fospeg, and its impact on cell cycle upon PDT of Huh7 hepatocellular carcinoma cell model. Photodiagnosis Photodyn Ther 2013; 10: 87-94.

37. Chen J, Xiao H, Huang Z, Hu Z, Qi T, Zhang B et al. MicroRNA124 regulate cell growth of prostate cancer cells by targeting iASPP. Int J Clin Exp Pathol 2014; 7: 2283-2290.

38. Lin BL, Xie DY, Xie SB, Xie JQ, Zhang XH, Zhang YF et al. Down-regulation of iASPP in human hepatocellular carcinoma cells inhibits cell proliferation and tumor growth. Neoplasma 2011; 58: 205-210.

39. Chen J, Xie F, Zhang L, Jiang WG. IASPP is over-expressed in human non-small cell lung cancer and regulates the proliferation of lung cancer cells through a p53 associated pathway. BMC Cancer 2010; 10: 694.

40. Li G, Wang R, Gao J, Deng K, Wei J, Wei Y. RNA interference-mediated silencing of iASPP induces cell proliferation inhibition and G0/G1 cell cycle arrest in U251 human glioblastoma cells. Mol Cell Biochem 2011; 350: 193-200.

41. Dong $\mathrm{P}$, Ihira K, Hamada J, Watari H, Yamada T, Hosaka M et al. Reactivating p53 functions by suppressing its novel inhibitor iASPP: a potential therapeutic opportunity in p53 wildtype tumors. Oncotarget 2015; 6: 19968-19975.

42. Lu J, Getz G, Miska EA, Alvarez-Saavedra E, Lamb J, Peck D et al. MicroRNA expression profiles classify human cancers. Nature 2005; 435: 834-838.

43. Kushibiki T, Hirasawa T, Okawa S, Ishihara M. Regulation of miRNA expression by low-level laser therapy (LLLT) and photodynamic therapy (PDT). Int J Mol Sci 2013; 14: 13542-13558.

44. Kushibiki T. Photodynamic therapy induces microRNA-210 and -296 expression in HeLa cells. J Biophotonics 2010; 3: 368-372.

45. Bach D, Fuereder J, Karbiener M, Scheideler M, Ress AL, Neureiter D et al. Comprehensive analysis of alterations in the miRNome in response to photodynamic treatment. $J$ Photochem Photobiol B 2013; 120: 74-81.

46. Miao KR, Xu W, Li JY. New member miRNA in p53 gene signal pathway - review. Zhongguo Shi Yan Xue Ye Xue Za Zhi 2009; 17: 500-503.

47. Rokavec M, Li H, Jiang L, Hermeking $H$. The p53/microRNA connection in gastrointestinal cancer. Clin Exp Gastroenterol 2014; 7: 395-413.

48. Davila ML. Photodynamic therapy. Gastrointest Endosc Clin N Am 2011; 21: 67-79.

49. Petrescu A, Marzan L, Codreanu O, Niculescu L. Immunohistochemical detection of p53 protein as a prognostic indicator in prostate carcinoma. Rom J Morphol Embryol 2006; 47: 143-146.

50. Wang B, Zhang L, Zhao L, Zhou R, Ding Y, Li G. LASP2 suppresses colorectal cancer progression through JNK/p38 MAPK pathway meditated epithelial-mesenchymal transition. Cell Commun Signal 2017; 15: 21.

51. Verma R, Gupta V, Singh J, Verma M, Gupta G, Gupta S et al. Significance of p53 and ki-67 expression in prostate cancer. Urol Ann 2015; 7: 488-493.

Cell Death and Disease is an open-access journal published by Nature Publishing Group. This work is licensed under a Creative Commons Attribution 4.0 International License. The images or other third party material in this article are included in the article's Creative Commons license, unless indicated otherwise in the credit line; if the material is not included under the Creative Commons license, users will need to obtain permission from the license holder to reproduce the material. To view a copy of this license, visit http://creativecommons.org/licenses/by/4.0/

(C) The Author(s) 2017 